\title{
Neurohormonal profile of patients with heart failure and diabetes
}

\author{
I.C.C. van der Horst, R.A. de Boer, H.L. Hillege, F. Boomsma, A.A. Voors, D.J. van Veldhuisen
}

Background. Neurohormonal activation is generally recognised to play an important role in the pathophysiology, prognosis and treatment of chronic heart failure (HF). While the number of patients with diabetes increases, little if anything is known about neurohormonal activation in $H F$ patients with diabetes.

Methods. The study population consisted of 371 patients with advanced HF who were enrolled in a multicentre survival trial. Ten different plasma neurohormones were measured (noradrenaline, adrenaline, dopamine, aldosterone, renin, endothelin, atrial natriuretic peptide [ANP], N-terminal (pro)ANP, brain natriuretic peptide [BNP] and $\mathrm{N}$-terminal (pro)BNP. Comparisons were made between patients with diabetes $(\mathrm{n}=81)$ and those without $(\mathrm{n}=290)$.

Results. At baseline, the two groups were comparable regarding age (mean 68 years), left ventricular ejection fraction (23\%), severity and aetiology of HF, while body weight was higher in those with diabetes (77.4 vs. 74.2 $\mathrm{kg}, \mathrm{p}=0.04)$. Most plasma neurohormones were similar between groups, but patients with diabetes had higher values of BNP (94 vs. 47

\author{
I.C.C. van der Horst \\ R.A. de Boer \\ A.A. Voors \\ D.J. van Veldhuisen \\ Department of Cardiology, University Medical Center \\ Groningen, University of Groningen, the Netherlands \\ H.L. Hillege \\ Departments of Cardiology, and Epidemiology, University \\ Medical Center Groningen, University of Groningen, the \\ Netherlands \\ F. Boomsma \\ Department of Internal Medicine, Section of Vascular \\ Pharmacology, Erasmus MC, Rotterdam, the Netherlands \\ Correspondence to: I.C.C. van der Horst \\ Department of Cardiology, University Medical Center \\ Groningen, University of Groningen, PO Box 30 001, 9700 RB \\ Groningen, the Netherlands \\ E-mail: i.c.c.horst@thorax.umcg.nl
}

$\mathrm{pmol} / 1, \mathrm{p}=0.03$ ), while a similar trend was observed for $\mathrm{N}$-terminal (pro)BNP (750 vs. 554 $\mathrm{pmol} / 1, \mathrm{p}=0.10)$. During almost five years of follow-up, 51/81 patients with diabetes died (63\%), as compared with 144 of 290 non-diabetic patients $(50 \%)$ who died $(\mathrm{p}=0.046)$. Natriuretic peptides and noradrenaline were the most powerful predictors of mortality in both diabetic and non-diabetic HF patients.

Conclusion. HF patients with diabetes have higher (N-terminal (pro)) BNP levels than nondiabetic patients, while other neurohormones are generally similar. Natriuretic peptides are also good prognostic markers in diabetic HF patients. (Neth Heart J 2010;18:190-6.)

Keywords: Heart Failure; Neurotransmitter Agents; Diabetes Mellitus

D iabetes is a significant independent risk factor for developing chronic heart failure (HF). The prevalence of diabetes in the general population is now at least $5 \%$, and current large trials show that this is around $30 \%$ in patients with chronic HF, while it may be close to $50 \%$ in those with acute HF. ${ }^{1-4}$ In the most recent Heart Failure Guidelines of the European Society of Cardiology the increasing importance of diabetes in HF is well recognised. ${ }^{5}$ In the Framingham study the relative risk for developing HF was 2.36 in diabetic men aged 45 to 74 years and 5.14 in diabetic women compared with nondiabetics. ${ }^{6}$ Patients with mild HF and diabetes have a worse prognosis than those without diabetes. ${ }^{7}$

Activation of neurohormonal systems plays an important pathophysiological role in $\mathrm{HF}^{8}$ Activation of these systems has been demonstrated in diabetes and is associated with arrhythmias, adverse ventricular remodelling, and (sudden) cardiac death..$^{9,10}$ Insulin resistance, as observed in diabetes, leads to activation of neurohormones, and this in turn leads to further insulin resistance. ${ }^{11}$ Therefore, diabetes may affect the degree of neurohormonal activation, and this potentially may be a contributing factor in the observed increased mortality 
among diabetic HF patients. Interestingly, while many studies are available regarding neurohormonal activation in non-diabetic HF patients, specific data in diabetic HF patients are not available.

We therefore studied a population of HF patients $^{12}$ in which extensive neurohormonal profiles were determined, ${ }^{13-15}$ and compared patients with diabetes with those without. In addition, we investigated the role of diabetes on long-term outcome in relation to these neurohormones.

\section{Methods}

\section{Study design and patient population}

All patients in the present study participated in a chronic HF survival trial (PRIME-II: Prospective Randomized study of Ibopamine on Mortality and Efficacy $)^{12}$ which investigated the effect of the oral dopamine agonist ibopamine on all-cause mortality in patients with moderate to severe HF. The present patient population consists of patients who were enrolled in the Netherlands only and in whom neurohormone levels were measured.

In short, patients aged 18 to 80 years were eligible for PRIME-II if they had signs and symptoms of moderate to severe chronic HF (NYHA class III to IV) despite optimal medical treatment. Drug treatment at baseline consisted of angiotensinconverting enzyme (ACE) inhibitors (unless intolerant), diuretics (in a dose of furosemide $80 \mathrm{mg}$ / day [or equivalent] if ACE inhibitors were not prescribed, or $40 \mathrm{mg} /$ day, when combined with an ACE inhibitor), and, if deemed indicated, digoxin and vasodilators. Left ventricular dysfunction had to be proved by one or more of the following techniques: (a) left ventricular ejection fraction (LVEF) $<0.35$ (measured by radionuclide or contrast ventriculography, or by echocardiography), (b) left ventricular internal end-diastolic diameter $>60 \mathrm{~mm}$, or a fractional shortening $<20 \%$ on echocardiography, or (c) cardiothoracic ratio (CTR) on chest $\mathrm{X}$-ray $>0.50$. Exclusion criteria included obstructive valve disease, obstructive or restrictive cardiomyopathy, potentially transient causes of chronic HF such as myocarditis, myocardial infarction or cardiac surgery within the previous three months, uncontrolled arrhythmias, uncontrolled hypertension, other non-cardiac high-risk underlying medical conditions including severe chronic obstructive pulmonary disease (COPD), and administration of investigational drugs within the last 30 days before randomisation. The investigation conforms to the principles outlined in the Declaration of Helsinki, and all patients gave their written informed consent before inclusion into the study.

\section{Study enrolment and follow-up}

Patient enrolment began in September 1992, but the PRIME-II study was prematurely discontinued in August 1995 when a significantly higher fatality rate was observed in the ibopamine group. At that time, 427 patients had been enrolled in the Netherlands. Of these patients, baseline neurohormone levels were measured in a total of 371 patients. ${ }^{15}$ Within two weeks after discontinuation of the study, all patients had discontinued study medication and patients were followed for at least two more years. During this time, patients were treated by their own physicians and continued standard medication for HF. At follow-up, all patients who had been alive at the end of PRIME-II were reassessed. All centres that had been involved in PRIME-II were visited, and a questionnaire was completed that included vital status. Of the patients who died, both the time of death as well as mode of death were investigated. If the data were not complete, general practitioners were contacted for additional information.

\section{Neurohormonal measurements}

Methods have been described in detail previously. ${ }^{13-15}$ Briefly, blood was collected from a peripheral intravenous cannula after patients had rested in the supine position for $>30 \mathrm{~min}$. Samples were poured into chilled $10-\mathrm{ml}$ heparinised polystyrene tubes containing $12 \mathrm{mg}$ of glutathione (for measurement of catecholamines, renin and aldosterone) and chilled $10-\mathrm{ml}$ tubes containing EDTA $(19 \mathrm{mg})$ and apronitin (1000 kIU) (for measurement of natriuretic peptides and endothelin). The tubes were centrifuged within $30 \mathrm{~min}\left(4^{\circ} \mathrm{C}, 10 \mathrm{~min}, 2000 \mathrm{x} \mathrm{g}\right)$ and the plasma was separated and stored in polyethylene tubes at $-70^{\circ} \mathrm{C}$. All samples were transported (on dry ice) to the Core Laboratory at the University Hospital Dijkzigt, Rotterdam, the Netherlands, where all measurements were performed.

\section{Statistical analysis}

The methods have been described before. ${ }^{12}$ Data are shown in means \pm standard deviation (SD). Categorical baseline data were compared between patients with or without diabetes by Fisher's exact test, or the $\chi^{2}$ test (NYHA class). Continuous baseline data were compared by Student's test or Wilcoxon two-sample test, when appropriate. The study focussed on the relation between the presence of diabetes and neurohormone levels at baseline, and the effect of diabetes on outcome. The effect on outcome was investigated with Cox proportional hazard regression analyses. Results were calculated as age- and sex-adjusted risk ratios (RR) and 95\% confidence intervals (CI). A number of neurohormones showed a log-linear functional shape with the response variable and were transformed to a $2-\log$ scale. This means that risk estimates should be interpreted as the relative risk if values were doubled. Proportional hazard assumption was assessed for every predictor variable. Kaplan-Meier curves were constructed that compared survival between 
patients with or without diabetes. P values $<0.05$ were considered statistically significant.

\section{Results}

Of the $371 \mathrm{HF}$ patients in whom neurohormonal profiles were available, 81 patients $(22 \%)$ had diabetes. Baseline characteristics of patients with and without diabetes are summarised in table 1. Overall, the two groups were rather comparable, but diabetic patients had a higher body weight $(77.4$ $\mathrm{kg}$ vs. $74.6 \mathrm{~kg}, \mathrm{p}=0.04$ ), and tended to have slightly higher systolic blood pressure (128 mmHg vs. 123 $\mathrm{mmHg}, \mathrm{p}=0.053$ ).

In table 2 the baseline levels of neurohormones are presented of both diabetic and non-diabetic patients, who were alive or not at the last follow-up. Plasma noradrenaline, adrenaline, dopamine, renin, aldosterone, endothelin, ANP and N-terminal (pro)ANP were all similar between the two groups. The median BNP level in patients with diabetes was higher ( $89 \mathrm{pmol} / 1$ vs. $47 \mathrm{pmol} / \mathrm{l}, \mathrm{p}=0.03)$, while values for $\mathrm{N}$-terminal (pro)BNP were slightly but not significantly higher $(\mathrm{p}=0.10)$, where it should be noted that the number of patients in whom N-terminal (pro)BNP samples were available was slightly lower (311 instead of 371 patients).

\section{Survival and neurohormones}

After a mean follow-up of almost five years, 195 of the patients had died: a total of $51(63 \%)$ patients with diabetes compared with $144(50 \%)$ patients without diabetes, hazard ratio 1.36 (95\% confidence interval 1.01 to $1.95, \mathrm{p}=0.046$ ). In figure 1 the Kaplan-Meier curve of patients with and with-

Table 1. Baseline demographic and clinical characteristics.

\begin{tabular}{|c|c|c|c|}
\hline & Diabetes & No diabetes & $P$ value \\
\hline Number of patients, (\%) & $81(22)$ & $290(78)$ & \\
\hline Age (years), mean \pm SD & $67.9 \pm 8.0$ & $67.7 \pm 8.0$ & 0.83 \\
\hline Female sex, n (\%) & $24(29)$ & $60(21)$ & 0.099 \\
\hline Heart rate (beats/min), mean \pm SD & $81 \pm 13$ & $81 \pm 15$ & 0.93 \\
\hline Weight (kg), mean \pm SD & $77.4 \pm 13.3$ & $74.2 \pm 12.0$ & 0.04 \\
\hline Systolic blood pressure (mmHg), mean \pm SD & $128 \pm 21$ & $123 \pm 17$ & 0.053 \\
\hline Diastolic blood pressure (mmHg), mean \pm SD & $76 \pm 9$ & $76 \pm 9$ & 0.98 \\
\hline NYHA class III, n (\%) & $54(67)$ & $199(69)$ & 0.79 \\
\hline NYHA class $>$ III, n (\%) & $27(33)$ & $91(31)$ & \\
\hline Duration of heart failure (years), mean $\pm S D$ & $4.2 \pm 3.3$ & $3.7 \pm 3.4$ & 0.29 \\
\hline Aetiology myocardial infarction, n (\%) & $59(74)$ & $220(76)$ & 0.66 \\
\hline Aetiology hypertension, n (\%) & $4(4.3)$ & $14(4.8)$ & 1.0 \\
\hline Aetiology cardiomyopathy, n (\%) & $13(16)$ & $48(17)$ & 1.0 \\
\hline $\mathrm{AF}, \mathrm{n}(\%)$ & $17(21)$ & $61(21)$ & 1.0 \\
\hline LVEF (\%), mean \pm SD & $23.7 \pm 8.0$ & $23.2 \pm 7.4$ & 0.58 \\
\hline \multicolumn{4}{|l|}{ Plasma laboratory values } \\
\hline - Sodium (mmol/l), mean \pm SD & $138 \pm 3.6$ & $139 \pm 3.4$ & 0.14 \\
\hline - Potassium (mmol/l), mean \pm SD & $4.2 \pm 0.6$ & $4.2 \pm 0.5$ & 0.42 \\
\hline - Creatinine $(\mu \mathrm{mol} / \mathrm{I})$, mean $\pm \mathrm{SD}$ & $116 \pm 31$ & $119 \pm 39$ & 0.53 \\
\hline - Estimated GFR, mean \pm SD & $62.2 \pm 25.4$ & $58.9 \pm 21.6$ & 0.31 \\
\hline - Urea $(\mathrm{mmol} / \mathrm{l})$, mean $\pm \mathrm{SD}$ & $10.0 \pm 4.2$ & $9.6 \pm 4.6$ & 0.47 \\
\hline \multicolumn{4}{|l|}{ Medication } \\
\hline - ACE inhibitor, n (\%) & $75(93)$ & $276(95)$ & 0.40 \\
\hline - $\beta$-blocker, n (\%) & $5(6.2)$ & $28(9.7)$ & 0.39 \\
\hline - Digoxin, n (\%) & $56(69)$ & $164(57)$ & 0.055 \\
\hline - Diuretics, n (\%) & $80(99)$ & $288(99)$ & 0.52 \\
\hline - Calcium channel blockers, n (\%) & $6(7.4)$ & $19(6.6)$ & 0.80 \\
\hline - Nitrates, n (\%) & $39(48)$ & $147(51)$ & 0.71 \\
\hline - Anticoagulant (coumarin), n (\%) & $54(67)$ & $210(72)$ & 0.33 \\
\hline - Antiplatelet agents, n (\%) & $11(14)$ & $50(17)$ & 0.50 \\
\hline - Antiarrhythmics, n (\%) & $11(14)$ & $58(20)$ & 0.26 \\
\hline
\end{tabular}


Table 2. Baseline plasma neurohormone levels in patients with and without diabetes.

\begin{tabular}{|c|c|c|c|}
\hline & Diabetes & No diabetes & P value \\
\hline Number of patients (\%) & $81(22)$ & $290(78)$ & \\
\hline Noradrenaline (pg/ml) & 507 (371-692) & 497 (362-700) & 0.52 \\
\hline Adrenaline (pg/ml) & $34(22-62)$ & $41(27-69)$ & 0.16 \\
\hline Dopamine (pg/ml) & $20(13-31)$ & $20(13-33)$ & 0.24 \\
\hline Aldosterone (pg/ml) & $93(65-205)$ & $120(67-228)$ & 0.54 \\
\hline $\operatorname{Renin}(\mu \mathrm{U} / \mathrm{ml})$ & $64(27-217)$ & 87 (41-229) & 0.46 \\
\hline Endothelin (pg/ml) & $4.9(3.2-10.1)$ & $5.6(3.5-13.9)$ & 0.12 \\
\hline ANP (pmol/l) & $103(76-196)$ & $104(59-177)$ & 0.66 \\
\hline N-terminal (pro)ANP (pmol/I) & $1174(651-1930)$ & 1067 (623-1743) & 0.99 \\
\hline BNP (pmol/l) & $94(26-145)$ & $47(17-108)$ & 0.03 \\
\hline N-terminal (pro)BNP (pmol/I) & $750(383-1460)$ & $554(253-1107)$ & 0.10 \\
\hline
\end{tabular}

out diabetes is represented. Of the 51 patients with diabetes who died, the cause was heart failure in 29 $(57 \%)$, sudden death in nine (18\%), myocardial infarction in four $(7.8 \%)$, cerebrovascular accident in four $(7.8 \%)$, neoplasm in two $(3.9 \%)$, and various in three $(5.9 \%)$ patients.

In patients without diabetes, the cause of mortality was progressive pump failure in $77(49 \%)$, sudden death in $45(32 \%)$, myocardial infarction in nine $(6.3 \%)$, cerebrovascular accident in two $(1.4 \%)$, neoplasm in seven $(4.9 \%)$, and various in four $(2.8 \%)$ patients.

Table 3 summarises the baseline neurohormone levels in patients with and without diabetes,

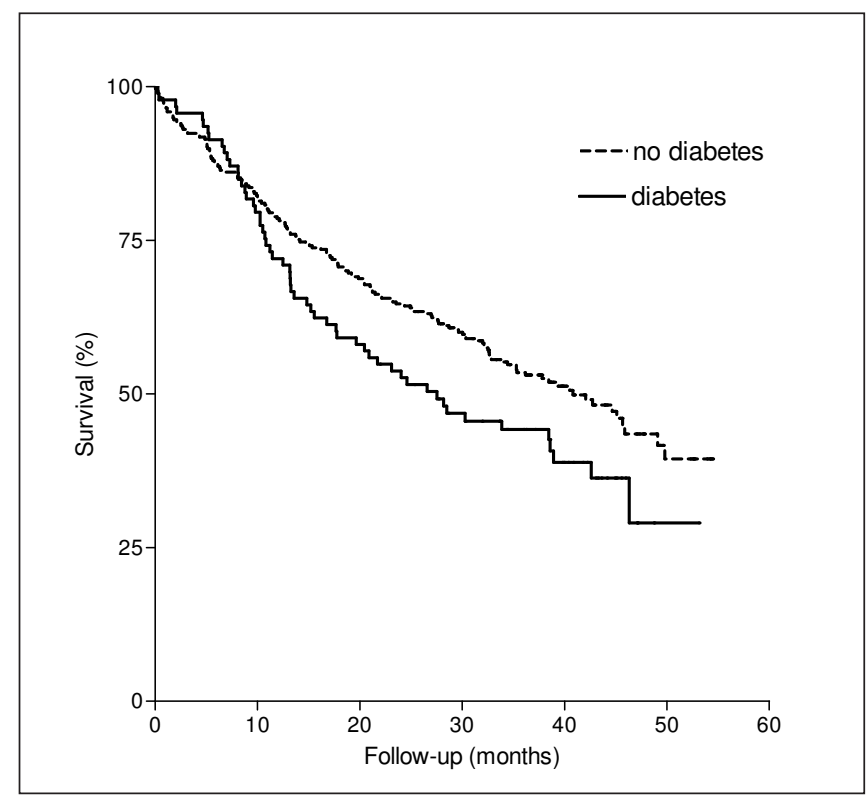

Figure 1. Kaplan-Meier curve of patients with and without diabetes. stratified to those who did or did not survive. In univariate analysis the levels of all neurohormones were higher in patients without diabetes who did not survive (table 3 ). In patients with diabetes noradrenaline, ANP, N-terminal (pro)ANP, BNP, and $\mathrm{N}$-terminal (pro)BNP were significantly higher in non-survivors (table 3 ).

\section{Discussion}

The main finding of the present study is that although the neurohormonal profiles of HF patients with diabetes were remarkably similar to those without diabetes, BNP (and to a lesser extent $\mathrm{N}$-terminal (pro)BNP) levels were significantly higher. Patients with diabetes in the present study had slightly higher body weight, but had the same LVEF and NYHA class, while age and sex were also similar, which makes them well comparable. The second finding is that BNP and $\mathrm{N}$-terminal (pro)BNP were the most powerful predictors of outcome, not only in patients without, but also in those HF patients with diabetes.

Plasma neurohormone levels are strong predictors of mortality in chronic $\mathrm{HF}^{16}$ and in the Valsartan Heart Failure Trial (ValHeFT) substudy BNP, noradrenaline, and renin were independently related to impaired long-term outcome, but stratification to diabetes was not performed. ${ }^{17}$ While diabetes is increasingly being recognised as an important factor in cardiovascular disease in general and HF in particular, it is remarkable that no data are available on neurohormonal activation in diabetic HF patients so far. Magnusson and colleagues studied 253 patients with type 2 diabetes and 230 matched control subjects without any overt heart disease (and HF) and observed higher $\mathrm{N}$-terminal (pro)BNP values in those with diabetes $(360.9 \mathrm{pmol} / 1$ vs. $302.7 \mathrm{pmol} / 1$ in controls, 


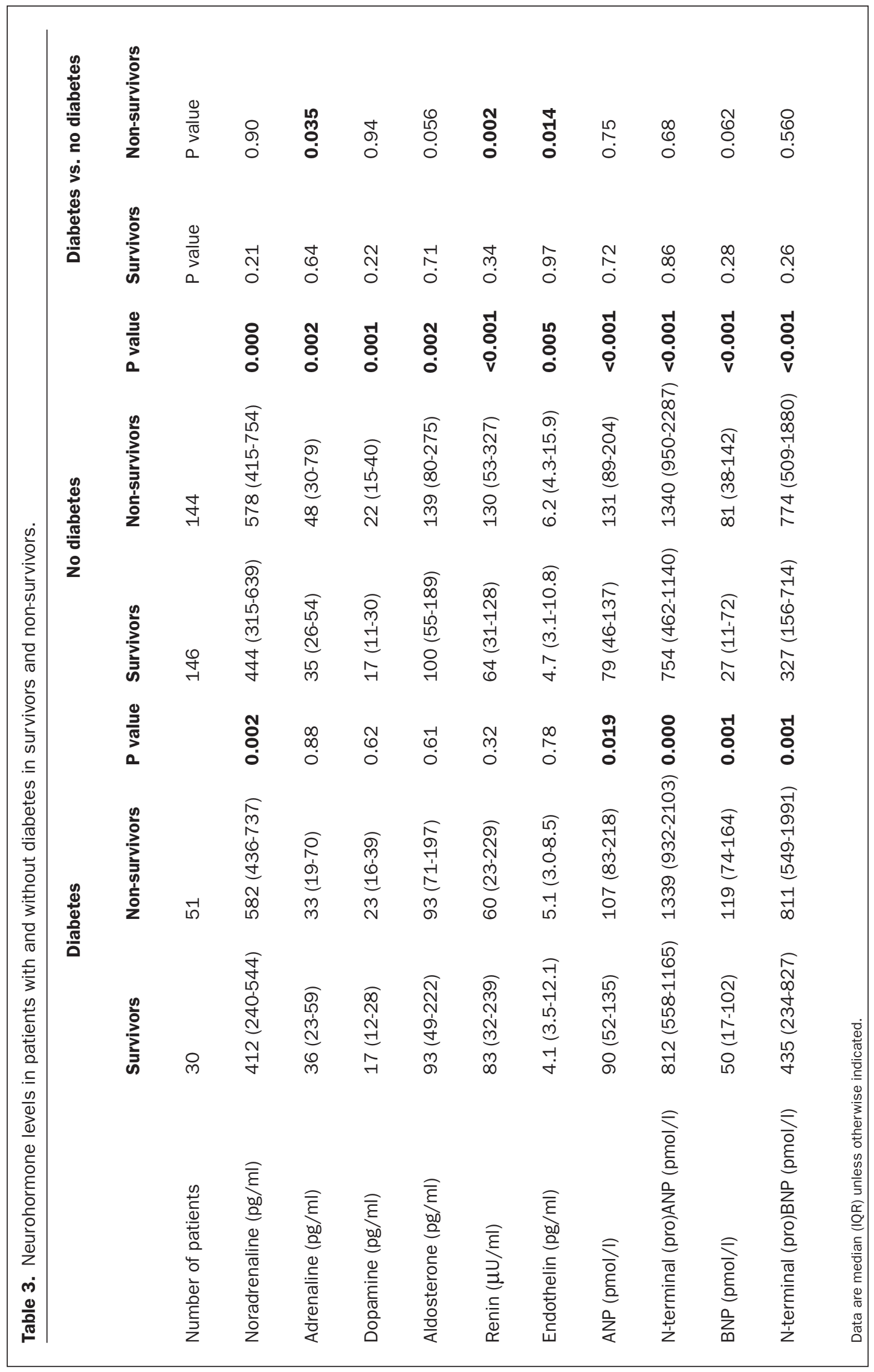


$\mathrm{p}<0.001) .{ }^{18}$ Bhalla et al. studied 482 patients with diabetes, and in the majority of them there was no suspicion of cardiac dysfunction; they found that there was a marked decrease in survival in the patient group with BNP $>120 \mathrm{pg} / \mathrm{ml} .{ }^{19}$ Moreover, Albertini et al. observed in 91 asymptomatic type 2 diabetics that BNP values were related to both diastolic and systolic LV dysfunction. ${ }^{20}$

The most likely explanation for the increased $\mathrm{BNP}$ (and N-terminal (pro)BNP) levels in patients with diabetes is the presence of diastolic dysfunction. Diastolic function was not measured in PRIME-II and there has only been general recognition of the importance of HF with preserved or normal ejection fraction in the last five to ten years. ${ }^{21}$ Diabetes and hypertension (but also ageing) are important factors leading to diastolic dysfunction, and all may initially be associated with normal left ventricular systolic function. However, increased insight into the pathophysiology of these diseases has also led to increased awareness and recognition of diastolic dysfunction. ${ }^{22}$ Accumulation of advanced glycation end-products (AGE)s, which occurs in diabetes, hypertension, but also in ageing, may potentially play a role in the development of diastolic dysfunction, ${ }^{23}$ but whether this may have therapeutic consequences is so far unknown, and indeed, the treatment of diastolic heart failure in the presence or absence of diabetes is hampered by the absence of evidence for a specific drug that can reduce mortality and morbidity in these patients. ${ }^{24}$

While BNP (and to a lesser extent $\mathrm{N}$-terminal (pro)BNP) were increased in HF patients with diabetes, it was remarkable that all other neurohormones were similar. Hyperglycaemia (and diabetes) has been associated with an up-regulated reninangiotensin-aldosterone system in subjects with normal LV function, and increased systemic and renal vasomotor tone. ${ }^{24,25}$ The endothelin system is also affected in patients with diabetes, and elevated levels of endothelin have been reported. ${ }^{26}$ In HF, however, haemodynamic alterations and abnormalities primarily drive the increased neurohormonal activation, ${ }^{9}$ and although all neurohormones were increased in the present study, parameters of the renin-angiotensin-aldosterone system as well endothelin were not increased in diabetic HF patients compared with HF patients without diabetes.

There are several potential limitations to the present study. This is a retrospective analysis, and treatment for HF was not standardised. Large differences exist in the treatment of HF not only within but also between countries ${ }^{27}$ which may have affected outcome. Also, the number of patients was relatively small and in a larger study, other patterns might have become apparent. Importantly, the use of $\beta$-blockers in the present study was low, as their value had not been proved at that time. ${ }^{3}$ In addition, $\beta$-blockers may affect plasma natriuretic pep- tide levels. Lastly, patients with diabetes are treated with hypoglycaemic drugs and insulin, so an effect of these drugs on neurohormones cannot be excluded. ${ }^{28}$

In conclusion, BNP (and to a lesser extent, Nterminal (pro)BNP) plasma levels are higher in patients with HF and diabetes, than in those without diabetes. This may be associated with the diastolic dysfunction observed in these patients, and may have an impact on prognosis. These data in HF patients with diabetes further establish the important role of these natriuretic peptides in (suspected) HF. ${ }^{29}$

\section{References}

1 De Groote P, Lamblin N, Mouquet F, et al. Impact of diabetes mellitus on long-term survival in patients with congestive heart failure. Eur Heart J. 2004;25:656-62.

2 Dries DL, Sweitzer NK, Drazner MH, Stevenson LW, Gersh BJ. Prognostic impact of diabetes mellitus in patients with heart failure according to the etiology of left ventricular systolic dysfunction. J Am Coll Cardiol. 2001;38:421-8

3 Jaarsma T, Van der Wal MH, Lesman-Leegte I, et al., for the COACH Study Group. Effect of moderate or intensive disease management program on outcome in patients with heart failure. The Coordinating study evaluating Outcomes of Advising and Counseling in Heart failure $(\mathrm{COACH})$. Arch Intern Med. 2008;168:316-24.

4 McMurray JJ, Teerlink JR, Cotter G, et al., for the VERITAS Investigators. Effects of tezosentan on symptoms and clinical outcomes in patients with acute heart failure. The VERITAS randomized controlled trials. JAMA. 2007;298:2009-19.

5 Dickstein K, Cohen-Solal A, Filippatos G, et al., on behalf of the Task Force for the Diagnosis and Treatment of Acute and Chronic Heart Failure 2008 of the European Society of Cardiology. Guidelines for the Diagnosis and Treatment of Acute and Chronic Heart Failure 2008. Eur J Heart Fail. 2008;10:933-89.

6 Kannel WB, Hjortland M, Castelli WP. Role of diabetes in congestive heart failure: the Framingham study. Am J Cardiol. 1974;34:29-34.

7 Shindler DM, Kostis JB, Yusuf S, et al. Diabetes mellitus, a predictor of morbidity and mortality in the Studies of Left Ventricular Dysfunction (SOLVD) Trials and Registry. Am J Cardiol. 1996;77:1017-20.

8 Levine TB, Francis GS, Goldsmith SR, Simon AB, Cohn JN. Activity of the sympathetic nervous system and renin-angiotensin system assessed by plasma hormone levels and their relation to hemodynamic abnormalities in congestive heart failure. Am J Cardiol. 1982;49:1659-66

9 Packer M. The neurohormonal hypothesis: a theory to explain the mechanism of disease progression in heart failure. J Am Coll Cardiol. 1992;20:248-54.

10 Schrier RW, Abraham WT. Hormones and hemodynamics in heart failure. N Engl J Med. 1999;341:577-85.

11 Miller JA, Floras JS, Zinman B, Skorecki KL, Logan AG. Effect of hyperglycaemia on arterial pressure, plasma renin activity and renal function in early diabetes. Clin Sci (Lond). 1996;90:189-95.

12 Hampton JR, Van Veldhuisen DJ, Kleber FX, et al, for the Second Prospective Randomised Study of Ibopamine on Mortality and Efficacy (PRIME-II) Investigators. Randomised study of effect of ibopamine on survival in patients with advanced severe heart failure. Lancet. 1997;349:971-7.

13 Tuinenburg AE, Van Veldhuisen DJ, Boomsma F, et. al. Comparison of plasma neurohormones in congestive heart failure patients with atrial fibrillation versus patients with sinus rhythm. Am J Cardiol. 1998;81:1207-10.

14 Hogenhuis J, Voors AA, Jaarsma T, Hillege HL, Boomsma F, Van Veldhuisen DJ. Influence of age on natriuretic peptides in patients with chronic heart failure: a comparison between ANP/NT-ANP and BNP/NT-proBNP. Eur J Heart Fail. 2005;7:81-6 
15 Rienstra M, Van Gelder IC, Van den Berg MP, Boomsma F, Van Veldhuisen DJ. Natriuretic peptides in patients with atrial fibrillation and advanced chronic heart failure: determinants and prognostic value of (NT-) ANP and (NT-pro) BNP. Europace. 2006;8:482-7.

16 Swedberg K, Eneroth P, Kjekshus J, Wilhelmsen L. Hormones regulating cardiovascular function in patients with severe congestive heart failure and their relation to mortality. CONSENSUS Trial Study Group. Circulation. 1990;82:1730-6.

17 Latini R, Masson S, Anand I, et al. The comparative prognostic value of plasma neurohormones at baseline in patients with heart failure enrolled in Val-HeFT. Eur Heart J. 2004;25:292-9.

18 Magnusson M, Melander O, Israelsson B, Grubb A, Groop L, Jovinge $\mathrm{S}$. Elevated plasma levels of Nt-proBNP in patients with type 2 diabetes without overt cardiovascular disease. Diabetes Care. 2004;27:1929-35

19 Bhalla MA, Chiang A, Epshteyn VA, et al. Prognostic role of B-type natriuretic peptide levels in patients with type 2 diabetes mellitus. J Am Coll Cardiol. 2004;44:1047-52.

20 Albertini JP, Cohen R, Valensi P, Sachs RN, Charniot IC. B type natriuretic peptide, a marker of asymptomatic left ventricular dysfunction in type 2 diabetic patients. Diabetes Metab. 2008;34:355-62.

21 Kindermann M, Reil JC, Piekse B, Van Veldhuisen DJ, Böhm M. Heart failure with normal left ventricular ejection fraction (HFNEF): what is the evidence? Trends Cardiovasc Med 2008; 2008; 18:280-92.
22 Pieske B, Wachter R. Impact of diabetes and hypertension on the heart. Curr Opin Cardiol. 2008;23:340-9.

23 Hartog JW, Voors AA, Bakker SJ, Smit AJ, Van Veldhuisen DJ. Advanced glycation end-products (AGEs) and heart failure; pathophysiological and clinical implications [review]. Eur J Heart Fail. 2007;9:1146-55

24 Voors AA, De Jong RM. Treating diastolic heart failure. Heart. 2008;94:971-2.

25 Miller JA, Floras JS, Zinman B, Skorecki KL, Logan AG. Effect of hyperglycaemia on arterial pressure, plasma renin activity and renal function in early diabetes. Clin Sci (Lond). 1996;90:18995.

26 Hopfner RL, Gopalakrishnan V. Endothelin: emerging role in diabetic vascular complications. Diabetologia. 1999;42:138394.

27 Van Veldhuisen DJ, Charlesworth A, Crijns HJGM, Lie KI, Hampton JR. Differences in drug treatment of chronic heart failure between European countries. Eur Heart J. 1999; 20: 666-72.

28 Nosadini R, Fioretto P, Giorato C, et al. Sodium metabolism in insulin dependent diabetic patients. Role of insulin and atrial natriuretic peptide. Diabete Metab. 1989;15:301-5.

29 Barents M, Van der Horst IC, Voors AA, Hillege JL, Muskiet FA, De Jongste MJ. Prevalance and misdiagnosis of chronic heart failure in nursing home residents: the role of B-type natriuretic peptide. Neth Heart J. 2008;16:123-8.

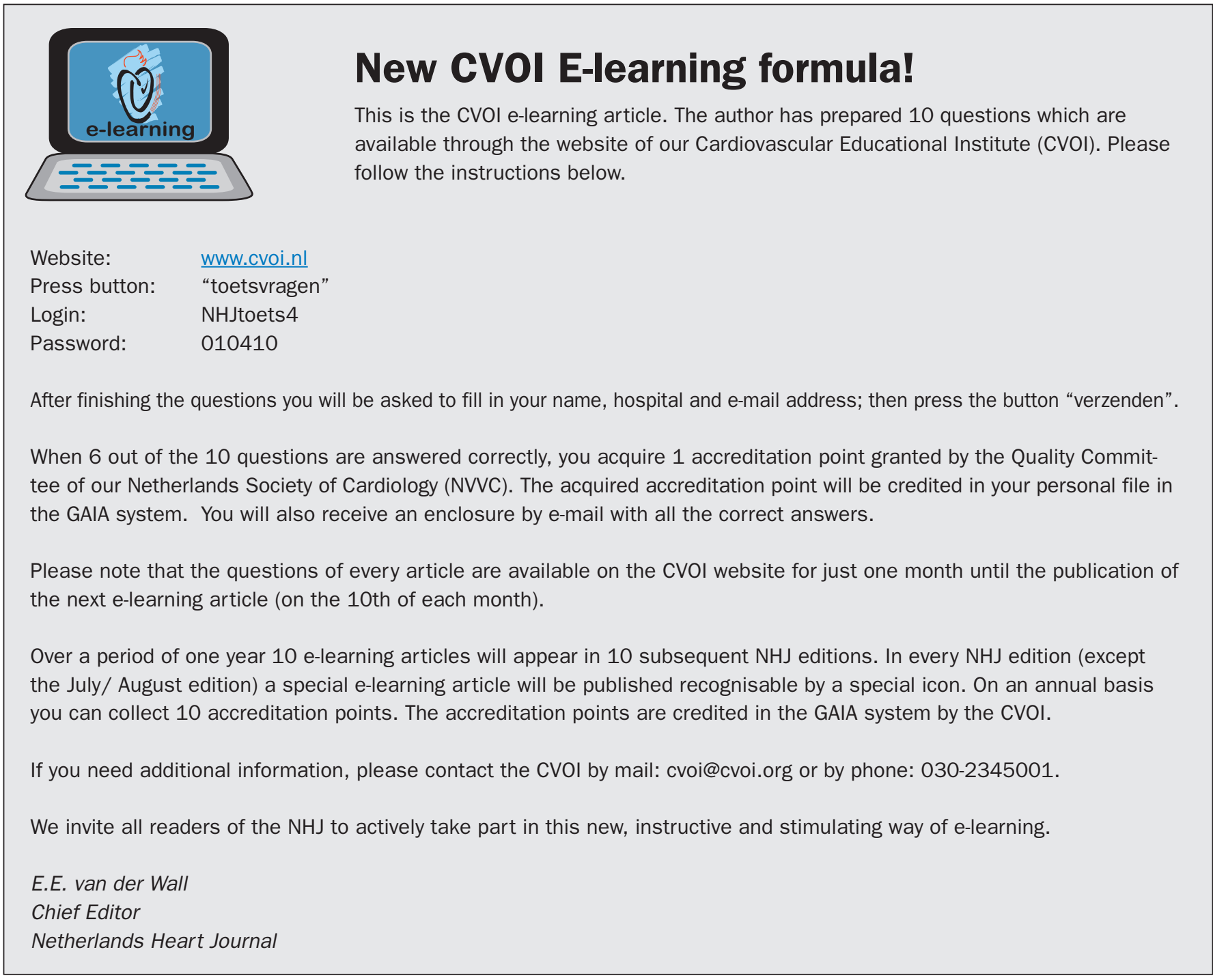

